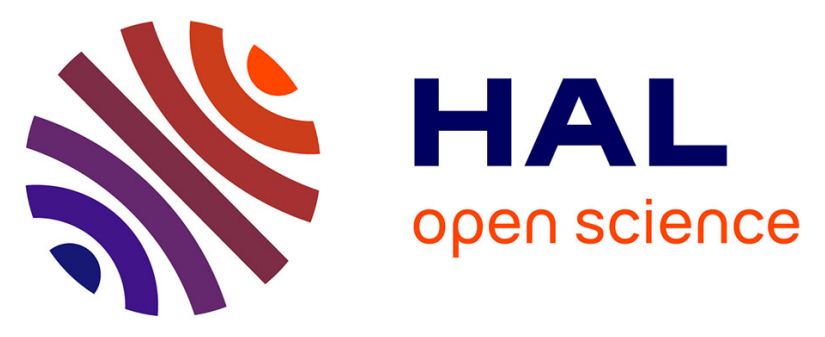

\title{
Semi-natural vegetation in agricultural land: European map and links to ecosystem service supply
}

Celia García-Feced, Christof Jakob Weissteiner, Andrea Baraldi, Maria Luisa

Paracchini, Joachim Maes, Grazia Zulian, Markus Kempen, Berien Elbersen, Marta Pérez-Soba

\section{To cite this version:}

Celia García-Feced, Christof Jakob Weissteiner, Andrea Baraldi, Maria Luisa Paracchini, Joachim Maes, et al.. Semi-natural vegetation in agricultural land: European map and links to ecosystem service supply. Agronomy for Sustainable Development, 2015, 35 (1), pp.273-283. 10.1007/s13593014-0238-1 . hal-01284260

\section{HAL Id: hal-01284260 https://hal.science/hal-01284260}

Submitted on 7 Mar 2016

HAL is a multi-disciplinary open access archive for the deposit and dissemination of scientific research documents, whether they are published or not. The documents may come from teaching and research institutions in France or abroad, or from public or private research centers.
L'archive ouverte pluridisciplinaire HAL, est destinée au dépôt et à la diffusion de documents scientifiques de niveau recherche, publiés ou non, émanant des établissements d'enseignement et de recherche français ou étrangers, des laboratoires publics ou privés. 


\title{
Semi-natural vegetation in agricultural land: European map and links to ecosystem service supply
}

\author{
Celia García-Feced • Christof Jakob Weissteiner • Andrea Baraldi • \\ Maria Luisa Paracchini • Joachim Maes • Grazia Zulian • Markus Kempen • \\ Berien Elbersen • Marta Pérez-Soba
}

Accepted: 24 June 2014 / Published online: 17 July 2014

(C) INRA and Springer-Verlag France 2014

\begin{abstract}
Semi-natural vegetation in agricultural land mainly includes extensively managed grasslands, agro-forestry areas and all vegetated features that are not used for crop production, such as hedgerows, buffer strips, field margins and woodlots. Semi-natural vegetation plays a major role in the supply of ecosystem services such as pollination, pest control, water quality control and erosion prevention. The efficiency of ecosystem services for agriculture should therefore depend upon the spatial distribution of semi-natural vegetation. In spite of such a relevance, semi-natural vegetation in agricultural land has never been mapped at the European scale. Therefore, we report here the first 1-km resolution map of semi-natural vegetation in agricultural land at the European Union scale. For that, we use an innovative convergence-ofevidence mapping method. We also present an assessment and a classification of the relation between semi-natural vegetation and ecosystem service supply at the regional scale. The major improvements in our mapping method are the following: (1) both large and small patches of perennial vegetation are detected in fine-resolution satellite images by incorporating the spectral rule-based preliminary classifier, (2) the identification
\end{abstract}

C. García-Feced · C. J. Weissteiner · M. L. Paracchini $(\bowtie) \cdot$

J. Maes · G. Zulian

European Commission, Joint Research Centre, Institute for

Environment and Sustainability, Via Fermi, 2749, 21027 Ispra, VA, Italy

e-mail: luisa.paracchini@jrc.ec.europa.eu

\section{A. Baraldi}

Department of Geographical Sciences, University of Maryland, 4321

Hartwick Rd, Suite 209, College Park, MD 20740, USA

\section{Kempen}

EuroCARE Bonn GmbH, Buntspechtweg 22, 53123 Bonn, Germany

B. Elbersen · M. Pérez-Soba

Alterra, Wageningen University and Research Centre, PO Box 47, 6700 AA Wageningen, The Netherlands of semi-natural grassland is enhanced, (3) European ancillary maps are used to help mapping of woody vegetation and identification of agro-ecosystems. Validation shows that our output map is $34.3 \%$ more accurate than pre-existing components. In addition, results show that regulating ecosystem services increase with the abundance of semi-natural vegetation in agricultural lands with a coefficient $R^{2}$ of 0.67 . The results also show no specific trend in relation to provisioning ecosystem services. These findings mean that semi-natural vegetation is usually beneficial for regulating services, whereas the relation to provisioning services is strictly contextdependent. Overall our study supports greening measures design in the frame of the Common Agricultural Policy for 2014-2020. Results also will help to identify green infrastructure elements and priority areas for ecological restoration.

Keywords Provisioning services $\cdot$ Regulating services · Spectral rule-based image classification · Common Agricultural Policy · Ecological focus areas · European Union biodiversity Strategy

\section{Introduction}

In the European continent, human pressure on the environment is known to be high on average. For example, $51.4 \%$ of the European Union's territory consists of managed land, i.e. urban, industrial and agriculture, according to Eurostat, and $97 \%$ of forests are under some type on management as well. In particular, agriculture is recognised as a main driver of biodiversity loss since the Common Agricultural Policy has supported mechanisation and intensification, especially in its first three decades of implementation, starting from the year 1962 until 1992, when the need to reverse this trend in a more environmentally sustainable farmland management was officially acknowledged (Gay et al. 2005). Embedded in the 
Common Agricultural Policy, several options for controlling and decreasing the pressure of farming practices on the environment, e.g. the preservation of high-nature value farming and incentives for planting hedgerows and seeding flower strips, are focused on preserving semi-natural vegetation in agricultural land (see Fig. 1), considered crucial for biodiversity maintenance and delivery of ecosystem services, such as pollination, pest control, water quality control and erosion prevention.

Semi-natural vegetation elements in agricultural land can be broadly divided into two core groups (Fig. 1): first, large areas of semi-natural vegetation, e.g. semi-natural grasslands, agro-forestry areas or traditional orchards, recognised as agrobiodiversity hotspots and therefore identified as high nature value farmland (Paracchini et al. 2008), and second, small-size unfarmed features, comprising both natural and anthropogenic components of agricultural landscapes, e.g. hedgerows, buffer strips, field margins or woodlots (Farmer et al. 2008).

The importance for nature conservation of semi-natural vegetation in agricultural areas is acknowledged by the existing literature (e.g. Wezel et al. 2013) as well as in recent agricultural and environmental regulations. Firstly, the Common Agricultural Policy 2014-2020 establishes as European Union's priorities in rural development policies the restoration, preservation and enhancement of ecosystems related to agriculture (Official Journal of the European Union 2013). It also recommends the maintenance of ecological focus areas as a greening measure. Secondly, the European Union biodiversity Strategy up to the year 2020 (European Commission 2011) requires the following: (i) as target 2 that, by 2020, ecosystems and their services are maintained and enhanced, by establishing green infrastructure and restoring at least $15 \%$ of degraded ecosystems, and (ii) as target 3 that, conservation of biodiversity shall be ensured together with an improvement in the provision of ecosystem services in areas under agriculture. In this context, green infrastructure is defined as "a strategically planned network of natural and semi-natural areas with other environmental features designed and managed to deliver a wide range of ecosystem services" (European Commission 2013).
Agricultural landscapes hosting semi-natural vegetation represent an example of an ecosystem with an intermediate level of disturbance, where ecosystems with certain degrees of extensive human management could reach a peak of services diversity. However, this type of land-use has never been studied and mapped in relation to its capacity to supply a diverse flow of ecosystem services, which is a pre-condition for a correct implementation of the European Union agricultural and environmental policies. In recent years, several European ecosystem service maps have been delivered (Maes et al. 2011, 2012a, b; Zulian et al. 2013), while new insights on the identification and mapping of semi-natural areas have been gained (Kempeneers et al. 2011; Paracchini et al. 2008; van der Zanden et al. 2013). Nonetheless, a full assessment of semi-natural vegetation distribution in agricultural land at the European spatial extent has not been accomplished yet, due to difficulties in identifying semi-natural grasslands and in mapping the semi-natural components of small size such as hedgerows or scattered trees (see Fig. 1) at large spatial scale. As a consequence, the contribution of agricultural land to the establishment of the green infrastructure and to ecosystem service supply in different regions at the European scale remains unknown to date.

To recover from this information lack, a novel continuous and categorical map of semi-natural vegetation in agricultural land is generated. The mapping work described in this paper is based on the analysis of satellite imagery and geospatial data; therefore, semi-natural feature identification is approached from the point of view of land use/land cover detection, which translates into mapping land cover elements, i.e. grasslands, shrubs and trees, that belong to the two semi-natural feature groups, and label them as semi-natural through ancillary information. The resolution of the analysis allows the identification of macro-structures that either cover an area sufficiently large to be detected with available data or have a high spectral contrast with the neighbouring fields such as hedgerows or woodlots. Micro-structures like field margins and flower strips are not detectable with the utilised data.

The original contribution of this paper is twofold. Firstly, it delivers the first $1-\mathrm{km}$ resolution continuous map of seminatural vegetation abundance in agricultural land at the
Fig. 1 Examples of European Union agricultural landscapes hosting different types of seminatural vegetation: semi-natural grasslands and agro-forestry areas (left) and small-size unfarmed features such as tree-lines and hedgerows (right)
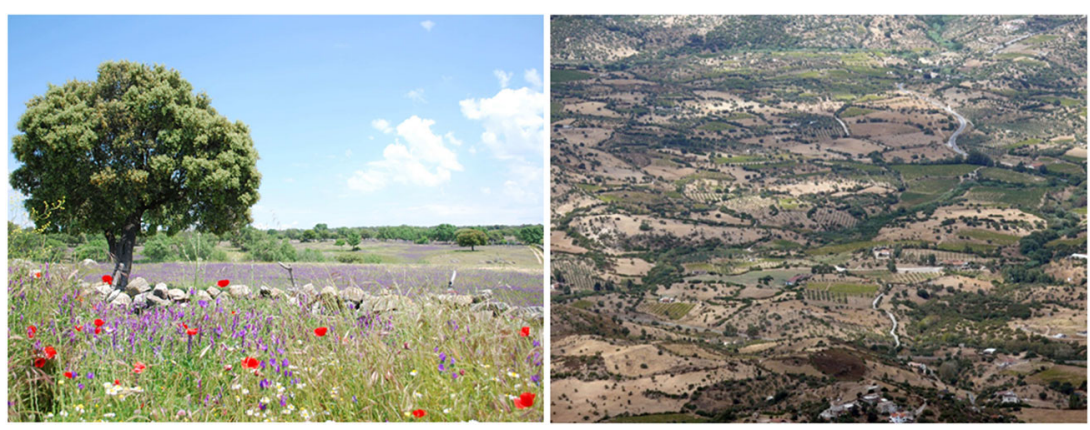
European spatial extent. Secondly, it provides a region-based assessment of the correlation between semi-natural vegetation and ecosystem service supply.

\section{Materials and methods}

2.1 Mapping the semi-natural vegetation land use/land cover elements

Figure 2 sketches the adopted workflow for a European Union-wide semi-natural vegetation mapping in agricultural land. The analysis focuses on land where agricultural management and farmers choices play a direct role in seminatural features maintenance, hence is restricted to the agricultural landscape, identified by the 1 ha-resolution COoRdinate INformation on the Environment (Corine) Land Cover 2006 map (European Environment Agency 2007) class 2, Agricultural areas, plus class 3.2.1, Natural grasslands, complemented with areas mapped as high nature value farmland (Paracchini et al. 2008) to include rough grazing.

\subsubsection{Stratification and identification of spectral categories compatible with semi-natural vegetation categories}

To provide the core identification of semi-natural vegetation, the spectral rule-based preliminary classifier (SRC), recently called Satellite Image Automatic Mapper ${ }^{\mathrm{TM}}$ (SIAMTM), is selected from the existing literature. To the best of these authors' knowledge, the spectral rule-based preliminary classifier is the first deductive (prior knowledge-based) inference system (expert system) in operating mode available for use in a hybrid (combined deductive and inductive) remote sensing image understanding system architecture (Baraldi and Boschetti 2012a, b; Baraldi et al. 2006). The spectral rulebased preliminary classifier is particularly suitable for detecting semi-natural vegetation patches because of the following: (a) it identifies image-objects as small as one pixel, whereas popular geographic object-based image analysis systems tend to remove all image-objects whose size is small; (b) it requires neither user-defined parameters nor training data samples to run, i.e. it is "fully automatic"; and (c) it is independent of the spatial resolution of the imaging sensor, i.e. it can be input with multi-spectral images whose spatial resolution ranges from coarse $(>1 \mathrm{~km})$ to very high $(<1 \mathrm{~m})$.

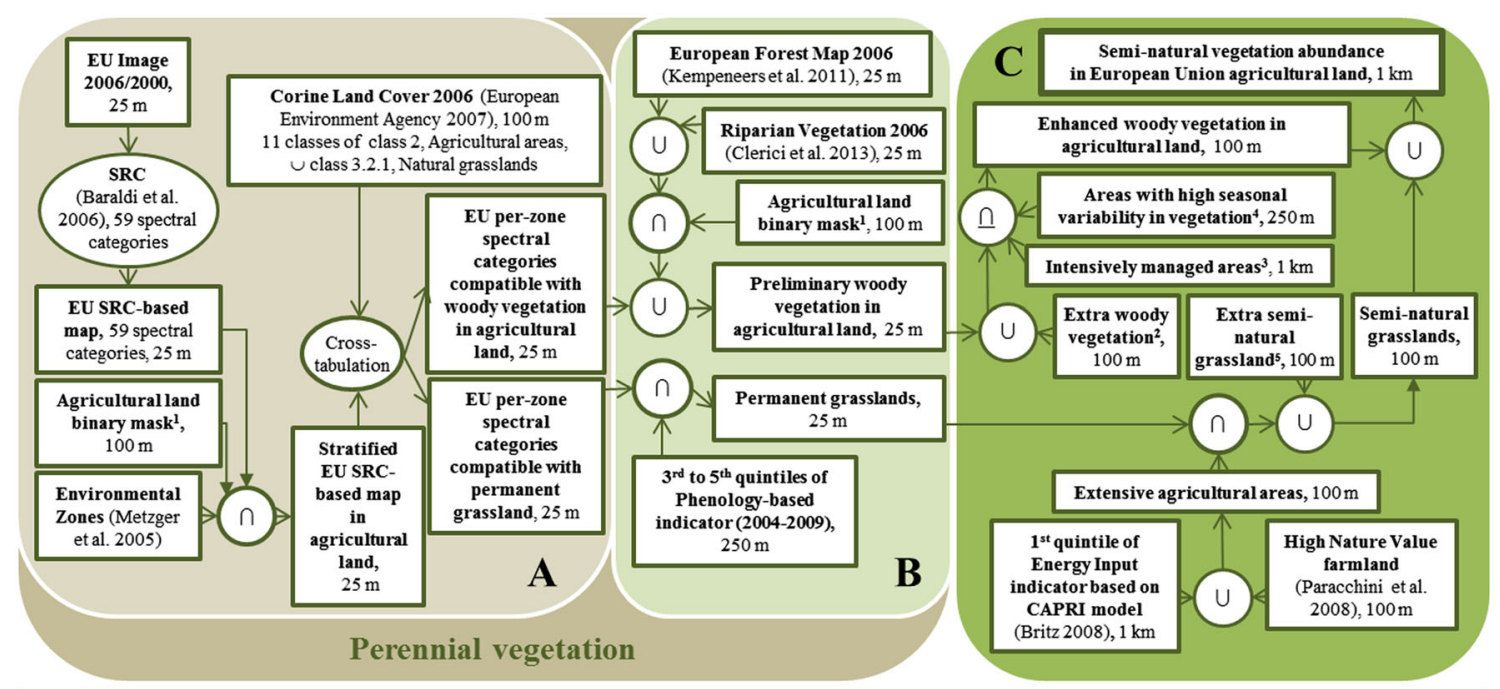

$\square{ }^{1}$ Agricultural land binary mask, $100 \mathrm{~m}=$ [Corine Land Cover 2006, class 2, Agricultural areas, $\cup$ class 3.2.1, Natural grasslands, $\left.100 \mathrm{~m}\right] \cup[$ High Nature Value farmland (Paracchini et al. 2008), $100 \mathrm{~m}$ ]

$\square{ }^{2}$ Extra woody vegetation in High Nature Value farmland binary mask, $100 \mathrm{~m}=$ [Corine Land Cover 2006, class 3.1, Forests, $\cup$ class 3.2.2, Moors and heathland, $\cup$ class 3.2.3, Sclerophyllous vegetation, $\cup$ class 3.2.4, Transitional woodland shrub, $\cup$ class 3.3.3, Sparsely vegetated areas, $\cup$ class 4.1 .2 , Peat bogs, $100 \mathrm{~m}$ ] $\cap$ [High Nature Value farmland (Paracchini et al. 2008), $100 \mathrm{~m}$ ]

$\square{ }^{3}$ Intensively managed areas binary mask, $1 \mathrm{~km}=\left[2^{\text {nd }}\right.$ to $5^{\text {th }}$ quintile of the Energy Input indicator based on the Common Agricultural Policy Regionalised Impact (CAPRI) model (Britz 2008), $1 \mathrm{~km}$ ] $\varrho$ [High Nature Value farmland (Paracchini et al. 2008), $100 \mathrm{~m}$ ]

$\square{ }^{4}$ Areas with a high seasonal variability in vegetation binary mask, $250 \mathrm{~m}=1^{\text {st }}$ or $2^{\text {nd }}$ quintile of the Ecological indicator based on phenology (2004-2009), $250 \mathrm{~m}$

$\square{ }^{5}$ Extra semi-natural grassland in High Nature Value farmland binary mask, $100 \mathrm{~m}=$ [Corine Land Cover 2006, class 4.1.1, Inland marshes, $\cup$ class 4.2.1, Salt marshes, $100 \mathrm{~m}$ ] $\cap$ [High Nature Value farmland (Paracchini et al. 2008), $100 \mathrm{~m}$ ]

Fig. 2 Original architecture of a categorical and continuous semi-natural vegetation mapping system based on a convergence-of-evidence approach and working at the European Union spatial extent. Processes and operators, either mathematical or logical, are represented as circles. Input/output information/datasets, e.g. either categorical or continuous 2-
D image-variables, are represented as squares. The following abbreviations are used: European Union (EU), spectral rule-based preliminary classifier (SRC), Common Agricultural Policy Regionalised Impact (CAPRI), logical "OR” ( $\cup)$, “AND” $(\cap)$ and "AND NOT” $(\bigcap)$ operators 
The selected input dataset of spaceborne multi-spectral images is the standard $25-\mathrm{m}$ resolution Image 2006 mosaic (Soille 2011). The standard Image 2006 mosaic consists of approximately 1,200 images, collected by the 4-band Indian Remote sensing Satellite (IRS)-P6 Linear Imaging SelfScanner (LISS)-III, mostly acquired through the year 2006 and radiometrically calibrated into top-of-atmosphere reflectance values. To fill up data holes located in the available Image 2006 mosaic, the Image 2000 mosaic is adopted instead (Nunes de Lima 2005). To cope with a high heterogeneity of image acquisition dates, covering the whole growing season, eight strata of satellite images are identified, to be considered as eight snapshots in time in which perennial vegetation is at a similar development stage. The stratification is based on the following: (a) recording year, 2006/2000; (b) vegetative period, from May to July/non-vegetative period, rest of months; and (c) Mediterranean/non-Mediterranean zones, derived from the European Environmental Zones map (Metzger et al. 2005).

Noteworthy, the spectral rule-based preliminary classifier's output map legend consists of a discrete and finite set of spectral categories (spectral-based semi-concepts), e.g. "Weak Vegetation", "Strong Shrub Rangeland", "Average Barren Land or Build-up", etc. whose semantic meaning is always equal or inferior, i.e. never superior, to that of traditional land cover/land use classes, for instance, "deciduous forest". The implemented spectral rule-based preliminary classifier, is derived from that described in Baraldi et al. (2006), where enough information is provided for the implementation to be reproduced, and is capable of detecting as output 59 spectral categories.

Among the detected 59 spectral categories, those matching the target semi-natural land cover classes (grassland and woody vegetation) must be identified by cross-tabulation against reference samples. In particular, the data-derived output map is cross-tabulated against the reference thematic map, identified as the 1 ha-resolution Corine Land Cover 2006 map, according to the following matching rules.

(a) Matching spectral categories with grassland in agricultural areas: identify the spectral categories featuring their highest occurrence in the Corine Land Cover class 2.3.1, Pastures, and class 3.2.1, Natural grasslands, and low occurrence in the class 2.1.1, Non-irrigated arable land;

(b) Matching spectral categories with woody vegetation in agricultural areas: identify the spectral categories featuring their highest occurrence in the Corine Land Cover class 2.4.3, Land principally occupied by agriculture, with significant areas of natural vegetation, and class 2.4.4, Agro-forestry areas.

These two matching rules identify 12 -of-59 spectral categories, including "Strong Vegetation", "Average Vegetation",
"Average Shrub and Brush Rangeland" and, exceptionally, the spectral category "Strong Barren Land", which is highly related to the Corine Land Cover class 2.4.4, Agro-forestry areas. The union of these 12 spectral categories selected from the aforementioned data-derived output map provides a first $25 \mathrm{~m}$ resolution binary map of perennial-like vegetation in agricultural land at the European scale.

\subsubsection{Identification of perennial vegetation}

In series with the block A (see Fig. 2), the block B pursues an enhanced mapping of perennial vegetation in agricultural land at the European Union spatial scale. Firstly, starting from the output of block A, the block B enhances detection of permanent grassland in agricultural areas as follows. Identified in Subsection 2.1.1, the spectral categories compatible with grassland within agricultural areas suffer from the fact that, being derived from sensory data covering one growing season only, they tend to include both permanent and temporary herbaceous vegetation. To distinguish permanent grasslands from arable lands or temporary grasslands, vegetation dynamics parameters are extracted from a 250 m-resolution Moderate Resolution Imaging Spectroradiometer (MODIS) imagederived time series (2004-2009) of 10-day maximum Normalized Difference Vegetation Index (NDVI) composites at European scale (Weissteiner et al. 2008). These vegetation parameters describe proportions of seasonally changing and permanent vegetation throughout a growing season, including timing of the vegetation peak. They are used to split the vegetative cycle in agricultural land into two, namely, a high-dynamic Normalized Difference Vegetation Index multi-temporal signature, typical of arable land due to ploughing/tilling, versus the rest of agricultural land types. Aridity information provided by the Desertification Indicators System for Mediterranean Europe (Brandt et al. 2003), environmental zoning (Metzger et al. 2005) and olive farming intensity data (Weissteiner et al. 2011) are added as ancillary information to discriminate arable land from stable or permanent vegetation. The resulting phenology-based indicator is discretized into quintiles, such that the 1st and 2nd quintiles are likely to represent temporary grasslands or arable lands, which are part of rotations. Therefore, the first two quintiles are removed from the binary map of perennial-like grasslands generated by Subsection 2.1.1, including the spectral category "Strong Barren Land" selected in Subsection 2.1.1, to make a better distinction between agro-forestry areas and arable lands.

Secondly, starting from the output of block A, the block B enhances detection of woody vegetation in agricultural areas by adding the European Forest Map 2006 (Kempeneers et al. 2011) and the Riparian Vegetation Map 2006 (Clerici et al. 2013).

A standard area frame survey, the Land Use and land Cover Area frame Sampling (LUCAS) 2006 (Jacques and Gallego 
2006), is selected as the source of ground-truth samples for validation of the block B output map components of perennial vegetation in agricultural land, namely, permanent grassland and woody vegetation in agricultural areas. Sampling points are located $2 \mathrm{~km}$ apart from each other and lie in the intersection of four 25-m resolution pixels of the output map. Hence, the map is resampled to $50-\mathrm{m}$ resolution and compared with the reference points belonging to the classes "permanent grasslands" and "wooded areas, shrub-lands", accounting for 126,387 points overall, in addition to "arable lands" and "permanent crops", accounting for additional 219,526 points. These accuracy estimates are compared with those obtained when only two pre-existing classification maps, the European Forest 2006 Map and the Riparian Vegetation Map 2006, are overlapped with Corine Land Cover 2006 map to identify woody vegetation in agricultural areas at the European Union scale.

\subsubsection{Detection of semi-natural grassland and enhanced woody vegetation to achieve the final semi-natural vegetation abundance map}

To form the final semi-natural vegetation abundance map, the goal of the block C (Fig. 2) is twofold. The first objective is to remove the intensively managed grassland component from the map of permanent grassland generated as output of the block B. To accomplish this objective, the block C employs two information sources: 1-km resolution Common Agricultural Policy Regionalised Impact model data (Britz 2008) and 100-m resolution High Nature Value farmland map (Paracchini et al. 2008). Among all possible indices calculated on the basis of the Common Agricultural Policy Regionalised Impact model applied to each of the so-called Homogeneous Spatial Mapping Units, the energy input in actual grassland expressed in $\mathrm{MJ} \mathrm{ha}^{-1}$ is selected as an indicator of the intensity of management. It includes organic and mineral manure, machinery/labour and irrigation. To cope with the inherent variability of indexes at the European scale, estimation of the energy input indicator is stratified by each of the 12 environmental zones considered in the study and partitioned into quintiles: the 1st quintile is considered the most likely representative of extensive grassland at $1-\mathrm{km}$ resolution. In addition, since it identifies areas where agriculture supports biodiversity, the High Nature Value farmland map, featuring 100-m resolution, is adopted as an alternative second source of evidence of the presence of semi-natural grassland. The map of permanent grassland in agricultural areas detected by the block B, aggregated by sum to $100-\mathrm{m}$ resolution, is then overlapped with the extensive agriculture area map. Finally, in order to produce the $100-\mathrm{m}$ resolution final semi-natural grassland map, the Corine Land Cover classes "Inland marshes" (class 4.1.1) and "Salt marshes" (class 4.2.1) in high nature value farmlands are also incorporated.
The second objective of the block $\mathrm{C}$ is to improve the preliminary map of woody elements in agricultural areas generated as output by the block B and later aggregated by sum to $100-\mathrm{m}$ resolution. Assuming that woody linear features such as tree-lines or hedgerows may not cover the total surface of the pixels, and in order to avoid overestimating the final semi-natural vegetation abundance, pixel values as mapped from satellite imagery are divided by two in the following cases: intensively managed areas represented by 2 nd to 5 th quintiles of the energy input indicator excluding high nature value farmlands and areas with a high seasonal variability in vegetation cover, corresponding to the 1 st or 2 nd quintile of the 250-m resolution phenology-based indicator (refer to Section 2.1.2). Secondly, the following classes of the High Nature Value farmland map are incorporated in the map, as cases in which land cover is the product of agricultural activities: Forests (class 3.1), Scrub and/or herbaceous vegetation association excluding Natural grasslands (classes 3.2.2, 3.2.3 and 3.2.4), Sparsely vegetated areas (class 3.3.3) and Peat bogs (class 4.1.2). Lastly, pixels corresponding to class 2.2.1 Vineyards are removed due to the difficulty of distinguishing them from semi-natural woody elements using satellite images.

The output map is transformed into a continuous map of semi-natural vegetation abundance, by aggregating by sum to $1 \mathrm{~km}$ resolution. It must be noted that this refers to the abundance of pixels identified as semi-natural vegetation. As a consequence, it should be regarded as a semi-quantitative indicator expressing the degree of presence of semi-natural vegetation features across the agricultural landscape, not as coverage in areal terms. Indeed, given that upscaling by aggregation to lower resolution leads to increasing error levels, these results overestimate actual semi-natural vegetation area. The same reasoning applies to further aggregation of the results to European Union regions.

\subsection{Assessing the relations between semi-natural vegetation} and ecosystem service supply

In the present study, pre-existing maps at 1-km resolution are used as the ecosystem services data source at European scale. "Provisioning" and "regulating and maintenance" ecosystem services are addressed, according to the categories identified by the Common International Classification of Ecosystem Services (Haines-Young and Potschin 2013), where provisioning services are defined as the goods or products obtained from ecosystems, like food, energy, livestock or timber production; regulating and maintenance services are defined as the benefits obtained from an ecosystem control of natural processes, like water availability through water regulation, climate stability through climate regulation, clean air availability through air quality and air flow regulation, erosion prevention, maintenance of soil fertility or maintenance of 
pollination. In the present study cultural services, i.e. the nonmaterial benefits obtained from ecosystem functions, are excluded from the analysis because the current source map is only based in one indicator related to recreation. Available maps concern: agricultural production expressed in energy $\left(\mathrm{MJ} \mathrm{ha}^{-1}\right.$ ), grazing livestock density (individuals $\mathrm{km}^{-2}$ ), timber stock $\left(\mathrm{m}^{3} \mathrm{ha}^{-1}\right)$, timber growth $\left(\mathrm{m}^{3} \mathrm{ha}^{-1}\right.$ year $\left.^{-1}\right)$ and annual water flow $(\mathrm{mm})$ for provisioning services; deposition velocity of particles in vegetation $\left(\mathrm{m}_{\mathrm{e}} \mathrm{ear}^{-1}\right)$, carbon storage (ton $\left.\mathrm{ha}^{-1}\right)$, carbon sequestration $\left(\mathrm{gC} \mathrm{m}^{-2}\right.$ year $\left.^{-1}\right)$, organic matter in topsoil concentration (\%), total amount of nitrogen retained per $\mathrm{km}$ of stream (\%), erosion control (ton $\mathrm{ha}^{-1}$ year $^{-1}$ ), water storage capacity $(\mathrm{mm})$ and relative pollination potential (dimensionless) for regulating and maintenance ecosystem services. A complete description of all datasets is available in Maes et al. (2011, 2012a, b) and Zulian et al. (2013). The overall values representing provisioning or regulating services are the result of summing the standardised values of the available indicators. For the standardisation $z$-score values are calculated and scaled 0 to 1. Regional mean is calculated afterwards.

\section{Results and discussion}

\subsection{Semi-natural vegetation abundance maps}

Figure 3 shows the resulting distribution of semi-natural vegetation across European Union-27 agricultural areas at 1-km resolution, regionally and by environmental zone. In line with theoretical expectations, most regions featuring intensive agriculture score low in values of semi-natural vegetation abundance. On the contrary, certain regions present a remarkable abundance of semi-natural vegetation within their agricultural areas. These regions are mainly located in the Mediterranean basin or are occupied by a large extent of mountainous areas like in Austria or Central-East of France, agro-forestry zones in Central-West of Spain and Portugal, or grasslands, e.g. in Northern Spain or the North and West of the United Kingdom. In accordance to this observation, environmental zones featuring the highest semi-natural vegetation abundance are the Alpine, both North and South, and Mediterranean Mountains, while the lowest abundance is featured by the Pannonian zone. Particularly, these agricultural landscapes that show a high abundance of semi-natural vegetation, even up to $100 \%$, may be associated to Type 1 of high nature value farmland, namely "farmland with a high proportion of semi-natural vegetation" (Paracchini et al. 2008). These are mostly areas of marginal agricultural production where extensive practices support a high biodiversity rate.

In Section 2.1.2, the block B detection of 25-m resolution perennial vegetation in agricultural areas, consisting of either permanent grassland or woody vegetation, is validated using Land Use and land Cover Area frame Sampling 2006 reference points. As reported, the sampling points are located at the intersection of four $25-\mathrm{m}$ resolution pixels. Results show that $82.3 \%$ of the perennial vegetation points, i.e. "permanent grasslands" and "wooded areas, shrub-lands" classes, is surrounded by at least one perennial vegetation pixel and $48.8 \%$ is surrounded by four perennial vegetation pixels. Instead, when the agricultural points, i.e. "arable lands" and "permanent crops" classes, are considered, these two percentage values decrease to 48 and $16.3 \%$, respectively. The analysis of the two disaggregated components of the block B's output map of perennial vegetation in agricultural areas shows that $63.3 \%$ of "permanent grasslands" points and $61 \%$ of "wooded areas, shrub-lands" points has at least one neighbouring pixel of, respectively, permanent grassland or woody vegetation.

Noteworthy, map accuracy of the woody vegetation in agricultural land increases by $34.3 \%$ when compared to the accuracy of the alternative map based exclusively on the two pre-existing European Forest 2006 Map and Riparian Vegetation Map 2006, which reflects a substantial improvement in the identification of woody elements in agricultural lands.

Methodological improvements mainly include the following: (i) detection of both large and small-sized perennial vegetation elements using recent fine-resolution $(25 \mathrm{~m})$ satellite images classified with the spectral rule-based preliminary classifier, (ii) removal of seasonally variable land assumed to be arable by incorporating an ad hoc phenology-based indicator, (iii) integration of pre-existing woody vegetation maps available at European spatial extent, (iv) integration of the High Nature Value farmland map, and (v) removal of intensively managed grasslands through an energy input indicator. The combination of these methodological enhancements has led to the generation of the presented spatial-explicit seminatural vegetation map covering both semi-natural grasslands and woody vegetation distribution at European Union-27 extent.

3.2 Regional assessment of the relations between semi-natural vegetation and ecosystem service supply

The regional assessment of semi-natural vegetation and supply of ecosystem services (Fig. 4) shows that there is a strong positive correlation $\left(R^{2}=0.67\right)$ between semi-natural vegetation abundance and the supply of regulating ecosystem services when all the agricultural lands are accounted.

The correspondence of the variables decreases when only arable lands are considered $\left(R^{2}=0.18\right)$, but continues to be positive. Instead, although clear outliers exist in this case, the majority of regions with low semi-natural vegetation abundance in their arable lands also show low values of regulating services. In this case, large semi-natural features like pastures 
Fig. 3 European Union-27 seminatural vegetation abundance maps at different aggregation levels (a 1-km resolution, b Regions corresponding to the Second level of the Nomenclature of Territorial Units for Statistics, and $\mathbf{c}$ environmental zones (Metzger et al. 2005)). Values are restricted to existing agricultural lands within each level, i.e. only Corine Land Cover classes 2, Agricultural areas and 3.2.1, Natural grasslands, plus the areas corresponding to High Nature Value farmland (Paracchini et al. 2008) are accounted. As a result of the improved mapping methodology, the maps integrate semi-natural grasslands and woody vegetation
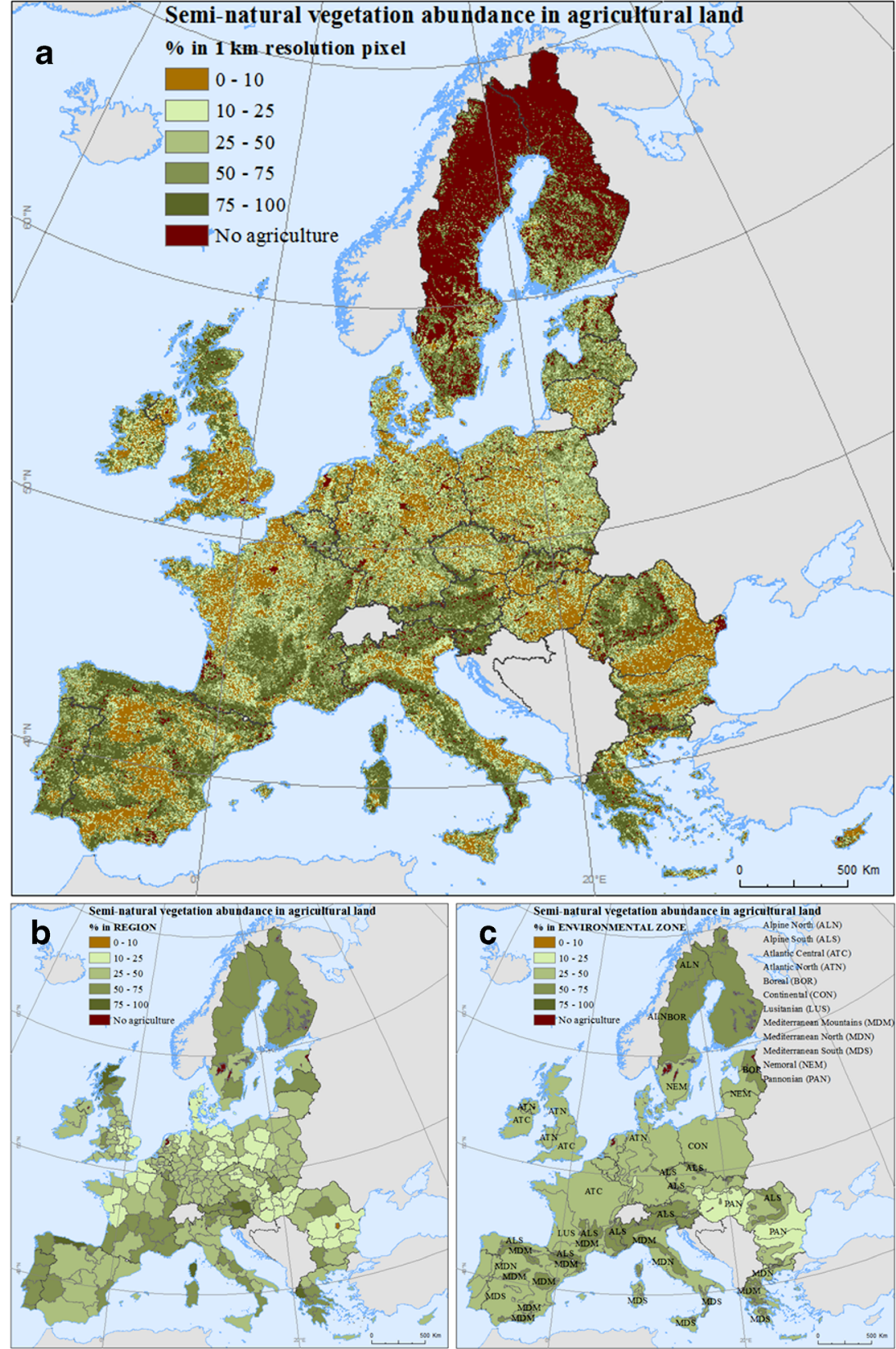

or agro-forestry areas, which have an inherent higher regulating services supply, are excluded, and the fact that the trend remains confirmed, though weaker, suggests that arable lands hosting a higher amount of semi-natural elements like hedgerows and woodlots are likely to provide a higher supply of regulating services.

On the contrary and most interestingly, Fig. 4 reveals that semi-natural vegetation abundance is not correlated to provisioning services supply in either agricultural land or arable land. This applies also if, among all provisioning services, agricultural production is considered, which confirms that the response of agricultural areas is strongly context-dependent (Qiu and Turner 2013) and that more research is needed to understand the link between provisioning and regulating services, and how the first can support the second at a large scale.

The proposed regional classification (Fig. 5) provides an integrated overview of the distribution of semi-natural vegetation, regulating services and provisioning services throughout European Union-27. In Fig. 5, the normalized means of the aforementioned three variables are adopted to separate values into two classes, below and above the median, i.e. $50 \%$ percentile, respectively. The presented classification is relative to the European median since it is not possible at present to identify an optimal performance status in terms of ecosystem services supply and presence of semi-natural vegetation. Noteworthy, this classification choice is arbitrary and 
Fig. 4 Correlation between seminatural vegetation abundance, provisioning and regulating ecosystem service supply in European Union-27 agricultural land. Top right: 3-D scatter plot of these three variables, located within all agricultural lands, defined as the combination between the Corine Land Cover class 2, Agricultural areas, and the High Nature Value farmland map (Paracchini et al. 2008). Depicted values correspond to the normalized means of these variables in each of the 259 regions corresponding to the second level of the Nomenclature of Territorial Units for Statistics, stratified by either agricultural land or arable land as a subset of agricultural land. Regression lines and their coefficient of determination $\left(R^{2}\right)$ are shown in the three scatter plots
SEMI-NATURAL VEGETATION ABUNDANCE AND ECOSYSTEM SERVICE SUPPLY
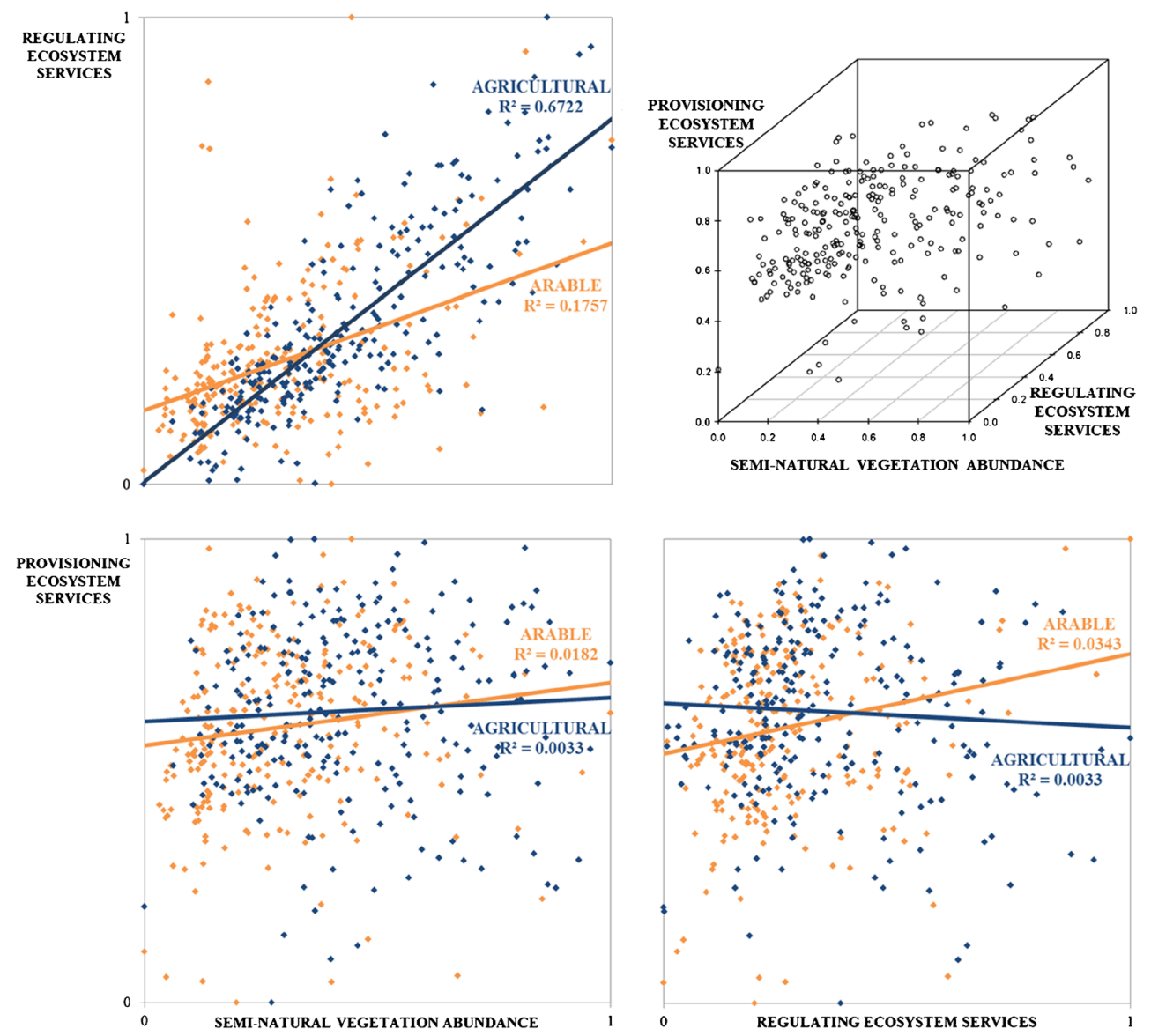

different options, alternative to Fig. 5, can be chosen for representation of results depending on prospective applications and improved knowledge on thresholds for ecological intensification.

The classification in Fig. 5 shows the spectrum of situations that occur in European Union-27. A group of regions (class 8) presents high values in the three variables. They are mainly located in the Boreal zone, in mountainous areas such as the South and East of France, Italy, Slovenia or Austria (Alpine South and Mediterranean Mountains zones), the Lusitanian zone (North of Spain and Portugal) or in the Atlantic North zone, e.g. Ireland or North and West of the United Kingdom. In some of these regions, grasslands are dominating, like in West Ireland or Northern Spain, others contain a considerable share of arable lands such as Piedmont and Umbria in Italy or Midi-Pyrenees in France. Overall, these regions show a good regional balance between ecosystem services provision and semi-natural vegetation abundance, therefore representing those multifunctional landscapes where ecosystem services supply in agricultural land is optimal. Unlike class 8, class 7 represents European Union regions with a high value of seminatural vegetation abundance and a high supply of regulating services, while provisioning services are low. These are mostly regions characterised by a high interspersion of natural and semi-natural vegetation in grazing areas, or scattered lowintensity arable land.

On the other hand, several regions have low values of regulating services despite the high presence of semi-natural elements. These regions seem to be dispersed around Europe, and correspond either to intensively managed lands with high provisioning services mainly present in Central Europe and United Kingdom (class 6) or low productive regions of Spain or Poland (class 5). In these cases, environmental conditions are limiting factors in ecosystem service supply.

A third typology (classes 3 and 4) shows a low abundance of semi-natural features coupled with a high supply of regulating services. This is the case of Andalusia in Spain, Eastern Bulgaria, Sicily and Northern regions in Italy. In this latter case, such a high score in regulating services is due to the averaging of values in regions where a variety of mountain areas, providing high regulating service values, and very intensive flatlands, characterised by high provisioning service values, are located. A fourth typology (class 2) is represented by regions where agricultural production and other provisioning services are high but both regulating services and seminatural vegetation abundance are low. These regions correspond to territories dominated by intensive agriculture in Northern Europe, mainly within the Atlantic Central zone. 


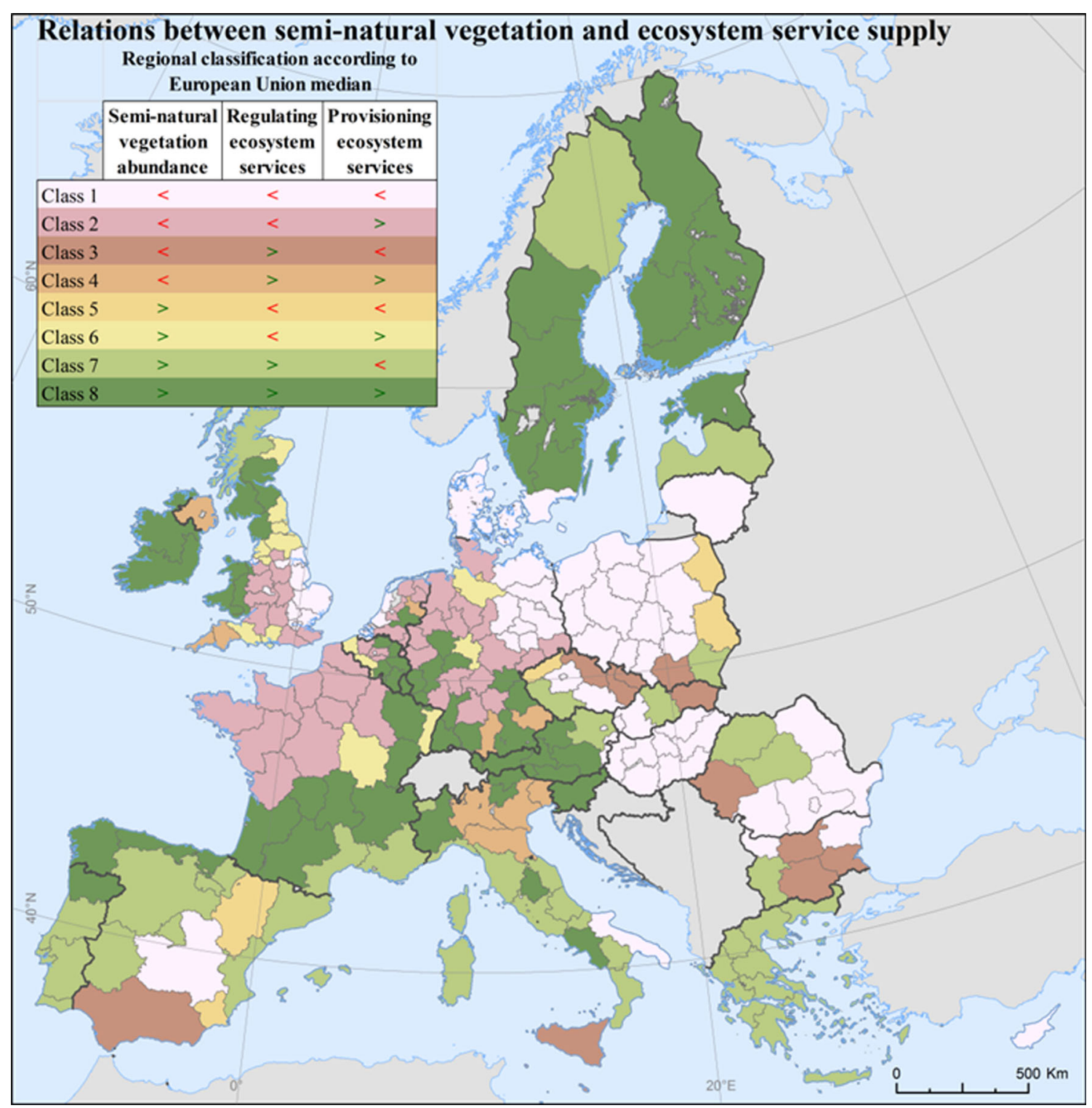

Fig. 5 Classification of European Union-27 regions (second level of the Nomenclature of Territorial Units for Statistics) in terms of semi-natural vegetation abundance and supply of regulating and provisioning ecosystem services. The normalized means of these three variables are used to

Lastly, there is a group of regions (class 1) that scores low in the three target variables. Many of these are located in Eastern Europe and include large parts of Hungary, Romania, Poland, Lithuania and Eastern Germany. Denmark and East of Anglia in the United Kingdom also belong to this typology. Dominance of arable lands with relatively low semi-natural vegetation abundance, coupled with limiting environmental conditions, and in some cases historical reasons such as land consolidation and removal of semi-natural elements, are main causes of the current situation. Together with regions belonging to class 2 , they correspond to the typology of regions where restoration activities may focus on introducing seminatural features in order to enhance regulating services supply. split values into two classes, below $(<)$ and above $(>)$ the median, i.e. $50 \%$ percentile. Only Corine Land Cover class 2, Agricultural areas, and High Nature Value farmland (Paracchini et al. 2008) are accounted for the classification

As previously mentioned, the Common Agricultural Policy 2014-2020 legislation (Official Journal of the European Union 2013) requires that at least $5 \%$ of the arable area of the holding for most farms with an arable area larger than 15 ha must be dedicated to maintain ecological focus areas, mainly composed by semi-natural vegetation features. The adoption of a landscape approach rather than a farm scale approach in the spatial distribution of such areas would on one hand raise the effectiveness of interventions by enhancing the supply of regulating ecosystem services and especially those, e.g. pollination or biocontrol, that support agricultural production (Tscharntke et al. 2012), on the other would enhance the contribution of agricultural lands to the European 
Union biodiversity to 2020 targets (European Commission 2011) concurring to the enhancement of the green infrastructure and a general support to biodiversity. In this regard, the proposed $1-\mathrm{km}$ resolution semi-natural vegetation mapping workflow can become a powerful tool for prioritizing areas of intervention based on ecosystem services analyses at varying reference spatial units such as province or landscape unit. It is worth underlining that presented results should not be used for assessments at fine scale, for which input data used are not suited, e.g. for the estimate of ecological focus areas following Common Agricultural Policy requirements. The presented maps aim at providing a general picture of existing trends among the analysed variables, and at highlighting those agricultural landscapes where an in-depth analysis should follow to identify management strategies to support the meeting of European Union policy goals. At this concern, an important complementary database is the Common Agricultural Policy Land Parcel Identification System, when in 2017 a reference layer to accommodate ecological focus areas will be included.

\section{Conclusion}

This study augments knowledge on agro-ecosystems by delivering the first Europe-wide map of semi-natural vegetation in agricultural lands and the first assessment of the relationship between semi-natural vegetation and the supply of ecosystem services. About the proposed information processing system, the following considerations hold:

(i) Selected from the existing literature, the spectral rulebased preliminary classifier, recently called Satellite Image Automatic Mapper ${ }^{\mathrm{TM}}$, guarantees consistent advancements in the identification of small spectral objects, by increasing of $34.3 \%$ the mapping accuracy of woody vegetation compared to pre-existing alternative maps, at zero costs in terms of user's interaction and in near realtime;

(ii) By considering as input small-size target objects and by implementing an improved differentiation of seminatural vegetation from intensive grasslands, the output map provides a further step in semi-natural vegetation mapping complementing pre-dated alternative maps (e.g. Kempeneers et al. 2011; Paracchini et al. 2008; van der Zanden et al. 2013);

(iii) The analysis of the relationships between the amount of semi-natural vegetation and the supply of ecosystem services at regional level shows that, first, agricultural landscapes characterised by a higher abundance of semi-natural vegetation do supply regulating services to a higher degree than intensively managed landscapes.
Second, there are examples of regions featuring a very high level of multifunctionality being located in the higher end of supply of both provisioning and regulating services in the European Union;

(iv) Indications on where to concentrate efforts on ecosystem restoration and Common Agricultural Policy greening, in particular ecological focus areas, can be drawn from the presented maps, for example, by keeping into consideration that the different performances of European regions strongly depend, besides historical development of agricultural practices and agricultural management strategies, on local environmental conditions, e.g. potential productivity and carrying capacity of the land. Finally, these results add new scientific evidence to the land sharing vs. land sparing debate (Grau et al. 2013).

Obviously, the optimisation of semi-natural features distribution is not the only answer to enhance sustainability of agriculture, but can surely improve the supply of those ecosystem services that are functional to agricultural production (Tscharntke et al. 2012) and, coupled to other practices (Wezel et al. 2013), concur to ecological intensification.

In conclusion, the presented work contributes to a better understanding of the inter-relations between semi-natural vegetation and ecosystem services in agricultural lands and, as a result, may be useful for a number of applications aimed at increasing the sustainability of agriculture and the resilience of agro-ecosystems.

Acknowledgments The authors would like to thank Nicola Clerici for his support with the riparian zones dataset.

\section{References}

Baraldi A, Boschetti L (2012a) Operational automatic remote sensing image understanding systems: beyond geographic object-based and object-oriented image analysis (GEOBIA/GEOOIA). Part 1: introduction. Remote Sens 4(9):2694-2735. doi:10.3390/rs4092694

Baraldi A, Boschetti L (2012b) Operational automatic remote sensing image understanding systems: beyond geographic object-based and object-oriented image analysis (GEOBIA/GEOOIA). Part 2: novel system architecture, information/knowledge representation, algorithm design and implementation. Remote Sens 4(9):2768-2817. doi: $10.3390 /$ rs 4092768

Baraldi A, Puzzolo V, Blonda P, Bruzzone L, Tarantino C (2006) Automatic spectral rule-based preliminary mapping of calibrated Landsat TM and ETM+ images. IEEE Trans Geosci Remote Sens 44(9):2563-2586. doi:10.1109/TGRS.2006.874140

Brandt J, Geeson N, Imeson A (2003) A desertification indicator system for Mediterranean Europe. DESERTLINKS Project (http://www. kcl.ac.uk/projects/desertlinks/). Accessed 20 May 2014

Britz W (2008) Automated model linkages: the example of CAPRI. Ger J Agric Econ 57 (8)

Clerici N, Weissteiner CJ, Paracchini ML, Boschetti L, Baraldi A, Strobl P (2013) Pan-European distribution modelling of stream riparian 
zones based on multi-source Earth observation data. Ecol Indic 24: 211-223. doi:10.1016/j.ecolind.2012.06.002

European Commission (2011) Our life insurance, our natural capital: an EU biodiversity Strategy to 2020. COM (2011) 244 final. Brussels

European Commission (2013) Green infrastructure (GI) - enhancing Europe's natural capital. COM (2013) 249 final. Brussels

European Environment Agency (2007) CLC2006 technical guidelines. EEA Technical Report No 17/2007. doi: 10.2800/12134

Farmer M, Cooper T, Baldock D, Tucker G, Eaton R, Hart K, Bartley J, Rayment M (2008) Final report - reflecting environmental land use needs into EU policy: preserving and enhancing the environmental benefits of unfarmed features on EU farmland. Contract No.ENV.B.1/ETU/2007/0033, report for DG Environment, IEEP, London

Gay SH, Osterburg B, Baldock D, Zdanowicz A (2005) Recent evolution of the EU Common Agricultural Policy (CAP): state of play and environmental potential. MEACAP WP6 D4b, Federal Agricultural Research Centre, Braunschweig, and Institute for European Environmental Policy, London

Grau R, Kuemmerle T, Macchi L (2013) Beyond 'land sparing versus land sharing': environmental heterogeneity, globalization and the balance between agricultural production and nature conservation. Curr Opin Environ Sustain 5(5):477-483. doi:10.1016/j.cosust. 2013.06.001

Haines-Young R, Potschin M (2013) CICES V4.3 Common International Classification of Ecosystem Services, Report prepared following consultation on CICES Version 4, August-December 2012. EEA Framework Contract No EEA/IEA/09/003

Jacques P, Gallego J (2006) The LUCAS 2006 project-A new methodology. European Commision, Joint Research Centre. http://mars.jrc. ec.europa.eu/Bulletins-Publications/The-LUCAS-2006-project-Anew-methodology. Accessed 20 May 2014

Kempeneers P, Sedano F, Seebach L, Strobl P, San-Miguel-Ayanz J (2011) Data fusion of different spatial resolution remote sensing images applied to forest-type mapping. IEEE Trans Geosci Remote Sens 49(12):4977-4986. doi:10.1109/TGRS.2011.2158548

Maes J, Paracchini ML, Zulian G (2011) A European assessment of the provision of ecosystem services: towards an atlas of ecosystem services. JRC Scientific and Technical Reports EUR 24750 EN. European Commission. Luxembourg: Office for Official Publications of the European Union. doi: 10.2788/63557

Maes J, Egoh B, Willemen L, Liquete C, Vihervaara P, Schägner JP, Grizzetti B, Drakou EG, Notte AL, Zulian G, Bouraoui F, Paracchini ML, Braat L, Bidoglio G (2012a) Mapping ecosystem services for policy support and decision making in the European Union. Ecosyst Serv 1(1):31-39. doi:10.1016/j.ecoser.2012.06.004

Maes J, Paracchini ML, Zulian G, Dunbar MB, Alkemade R (2012b) Synergies and trade-offs between ecosystem service supply, biodiversity, and habitat conservation status in Europe. Biol Conserv 155: 1-12. doi:10.1016/j.biocon.2012.06.016
Metzger MJ, Bunce RGH, Jongman RHG, Mücher CA, Watkins JW (2005) A climatic stratification of the environment of Europe. Glob Ecol Biogeogr 14(6):549-563. doi:10.1111/j.1466-822x.2005. 00190.x

Nunes de Lima MV (ed) (2005) Image2000 and CLC2000 Products and methods. EUR 21757 EN. European Commission, Joint Research Centre, Institute for Environment and Sustainability, Ispra, Italy

Official Journal of the European Union (2013) Regulation (EU) No 1307/2013 of the European Parliament and of the Council of 17 december 2013 establishing rules for direct payments to farmers under support schemes within the framework of the common agricultural policy and repealing Council Regulation (EC) No 637/2008 and Council Regulation (EC) No 73/2009. Official Journal of the European Union, L 347/608, 20.12.2013

Paracchini ML, Petersen J-E, Hoogeveen Y, Bamps C, Burfield I, van Swaay C (2008) High nature value farmland in Europe. An estimate of the distribution patterns on the basis of land cover and biodiversity data. JRC Scientific and Technical Reports EUR 23480 EN. Luxembourg: Office for Official Publications of the European Union. doi: 10.2788/8891

Qiu J, Turner MG (2013) Spatial interactions among ecosystem services in an urbanizing agricultural watershed. PNAS 110(29):1214912154. doi:10.1073/pnas. 1310539110

Soille P (ed) (2011) The IMAGE-2006 Mosaic Project. JRC Scientific and Technical Reports EUR 23755 EN. European Commission. Luxembourg: Office for Official Publications of the European Union. doi: 10.2788/25572

Tscharntke T, Clough Y, Wanger TC, Jackson L, Motzke I, Perfecto I, Vandermeer J, Whitbread A (2012) Global food security, biodiversity conservation and the future of agricultural intensification. Biol Conserv 151(1):53-59. doi:10.1016/j.biocon.2012.01.068

van der Zanden EH, Verburg PH, Mücher CA (2013) Modelling the spatial distribution of linear landscape elements in Europe. Ecol Indic 27:125-136. doi:10.1016/j.ecolind.2012.12.002

Weissteiner CJ, Sommer S, Strobl P (2008) Time series analysis of NOAA AVHRR derived vegetation cover as a means to extract proportions of permanent and seasonal components at pixel level. EARSeL eProceedings 7(1):11-20

Weissteiner CJ, Strobl P, Sommer S (2011) Assessment of status and trends of olive farming intensity in EU-Mediterranean countries using remote sensing time series and land cover data. Ecol Indic 11(2):601-610. doi:10.1016/j.ecolind.2010.08.006

Wezel A, Casagrande M, Celette F, Vian J-F, Ferrer A, Peigné J (2013) Agroecological practices for sustainable agriculture. A review. Agron Sustain Dev. doi:10.1007/s13593-013-0180-7

Zulian G, Maes J, Paracchini ML (2013) Linking land cover data and crop yields for mapping and assessment of pollination services in Europe. Land 2(3):472-492. doi:10.3390/land2030472 